\title{
ATTRACTIVENESS OF RURAL AREAS: DEVELOPMENT OF INITIAL DEFINITION
}

\author{
Ligita Melece ${ }^{1}$, Pavel Kogut ${ }^{2}$, Ilze Shena ${ }^{1}$ \\ ${ }^{1}$ Institute of Agricultural Resources and Economics, Latvia; ${ }^{2} 21 \mathrm{c}$ Consultancy, United Kingdom \\ ligita.melece@arei.lv, pavel.kogut@21cconsultancy.com, ilze.shena@arei.lv
}

\begin{abstract}
There has been a growing interest in assessing the attractiveness of territories, especially rural ones, from the perspective of stakeholders, such existing exiting rural populations, potential newcomers and new entrants. As part of the PoliRural project, the aim of the presented research was determined - to create the initial vision (i.e. definition) of rural attractiveness by considering factors that influence people's desire to live and work in rural areas. To that end, a mixed method approach combining qualitative and quantitative techniques was used. The overall research framework was executed in several sequential steps: brainstorming, literature review, survey questionnaire, data analysis, and evaluation. In defining rural attractiveness, two different but interrelated perspectives were considered, one focusing on people, the other on the entire rural ecosystem. During internal survey of project participants—respondents prioritized definitions by assigning points or scores on their preferred definition. Accordingly, an initial vision's definition of rural attractiveness was created based on the highest assessment score.
\end{abstract}

Keywords: rural, attractiveness, vision, well-being, survey.

\section{Introduction}

Changes in rural areas, such as depopulation, land abandonment and the loss of biodiversity, may proceed very slowly, yet are often irreversible. Over the past twenty-five years, rural regions have experienced rapidly shrinking population, as people, especially young adults, have migrated to cities with the lure of better paid jobs, modern affordable homes and more exciting lifestyles. The oldfashioned image of the rural idyll is seemingly no longer valid. Policymakers can steer these developments in order to reduce their negative impacts, but this requires knowing whether current policy instruments are effective, who is benefiting from them and in what measure, what driving forces will be most influential and how will they affect people, profits and land-use [1-2].

On the EU level, concerns about rural exodus and youth-drain pose "...the need to ensure that rural areas and communities (countryside, farms, villages, and small towns) remain attractive places to live and work by improving access to services and opportunities" [4]. It is often argued that policies should promote rural quality of life, and meet the aspirations of rural youth for diverse and wellrewarded employment, while at the same time facilitating generational renewal. Additionally, it is important to strengthen the identity of rural communities in order to spur growth and make rural areas attractive for people to live and work at different stages of their lives [4].

Whereas some rural areas represent the most prosperous and well performing areas in the country, others are experiencing depopulation, demographic ageing and high levels of poverty, and land abandonment. Rural attractiveness is about rural development that encompasses the diversity of rural life, places and professions. It is about creating conditions that entice people to invest, relocate, live, work and marry in rural areas. Attractive rural places are valuable environments where biodiversity and natural heritage are safeguarded [4].

In response to the need for a more strategic approach to rural development, a Horizon 2020 project titled "Future Oriented Collaborative Policy Development for Rural Areas and People PoliRural" was created and funded under the EU's research and innovation programme. PoliRural focuses on policy making as the main instrument for advancing rural attractiveness. The ambition is to make rural places and professions more attractive for established rural populations and recent or potential newcomers [2].

The literature review indicates that there is a growing interest in and importance of assessing the attractiveness of territories, especially rural ones, from the perspective of stakeholders, such as existing rural populations, potential newcomers and new entrants. The wellbeing of various sociodemographic groups living in rural areas is gaining in importance [4].

Among the aims of the project is the creation of a robust vision's definition of rural attractiveness, one that characterizes and incorporates factors influencing the attractiveness of rural areas as desirable places to live and work, and that helps explain changes in people's motivation to 
stay or relocate to/from a rural area. In other words, to become a newcomer or new entrant to a countryside.

Therefore, the aim of the presented research was - to create initial or first vision's definition of rural attractiveness.

\section{Materials and methods}

The use of different materials is envisaged throughout the project and their application depends on the stage of study: (i) literature - contribution of scholars (e.g. academic literature, reports), project results relevant to the topic, as well as guides and recommendations of different EU institutions (European Parliament and Council, EC, EU-level organizations etc.); (ii) output of brainstorming session (PoliRural partners); (ii) results of questionnaire survey (PoliRural consortium partners).

A mixed research method combining qualitative and quantitative methods was used to provide an initial definition of rural attractiveness [5-6].

A comprehensive literature review was conducted to obtain a holistic overview of the interrelated objectives/ tasks: (i) attractiveness, particularly the rural one, as well as related factors (e.g. quality of life) and resources (e.g. rural or territorial capital, rural assets); (ii) activities and opportunities to increase the rural attractiveness. Literature review was carried out in two ways: 1) the systematic review approach [7]; and 2) integrative review approach [8]. The chosen method summarizes past empirical and theoretical literature to provide a deep understanding of a particular phenomenon or problem. When used correctly, it has the potential to create an initial vision of rural attractiveness, as well as to raise awareness of rural stakeholders' needs and challenges, particularly those experienced by the disadvantaged groups, among scholars, experts and policy makers.

Reporting data (completed questionnaires) received from PoliRural partners was summarized, complimented and analysed. The ranking of rural attractiveness vision was carried out using descriptive statistics [9].

\section{Methodology}

The role of vision in sustainability research and problem solving has been recognized in academic and policy research, and visioning has been widely integrated in comprehensive procedural frameworks leading from problem definition to strategy implementation [10]. In PoliRural, the development of an initial definition of rural attractiveness, as well as the identification of assets, needs challenges, opportunities and enablers was performed in several steps (Fig. 1).

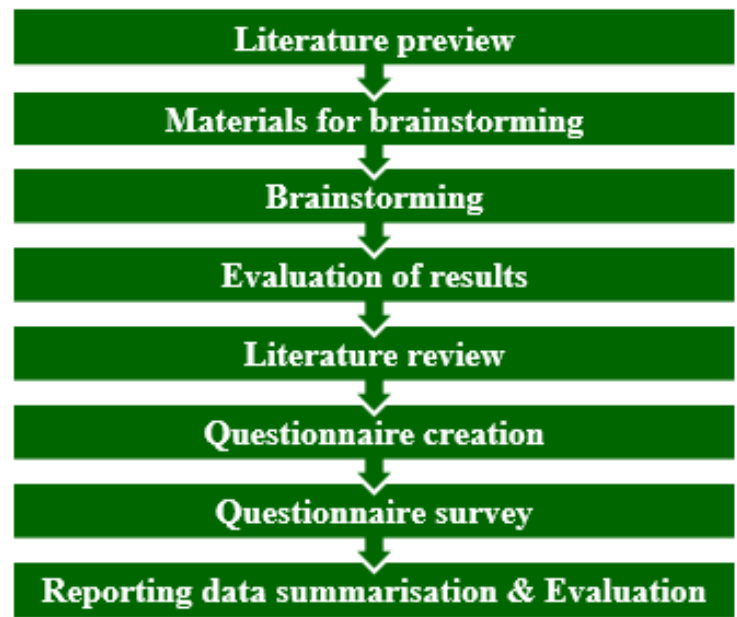

\section{Fig. 1. Steps of rural attractiveness initial vision's development}

A questionnaire survey, which provides an easy and flexible way to collect data compared to other methods [11], was adopted (i) to choose the most appropriate vision's definition, one that better characterizes rural attractiveness; (ii) to identify rural assets; and (iii) to identify needs and challenges, opportunities and enablers of rural areas. To evaluate data on rural assets, needs, challenges, opportunities and enablers, qualitative research methods [12] were used, such as the content analysis [13]. 


\section{Results and discussion \\ Brainstorming}

Brainstorming started with an introduction by the moderator. The first task was to identify and record on post-its: a) rural assets, b) rural needs and challenges, c) rural opportunities and enablers. Participants were divided into groups, each of which had to discuss and summarize the results before finally presenting them to the rest of the audience (Fig. 2).

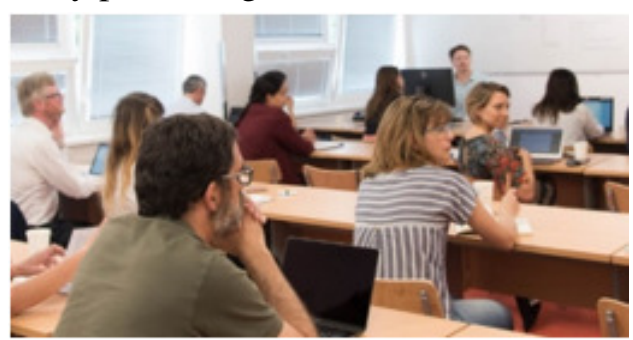

a)

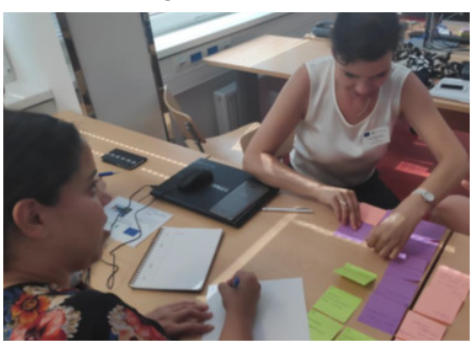

b)

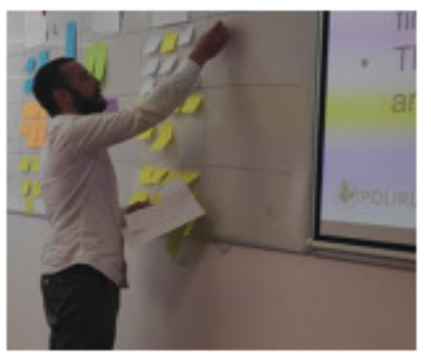

c)

Fig. 2. Brainstorming session: $a$ - initial discussion; $b$ - group discussion; $\mathrm{c}$ - presentation of group's results

The second task was to create and define the vision of rural attractiveness. Then the definition of rural attractiveness was tested from the perspective of hypothetical stakeholders (imaginary persons). The main questions to address were: is the definition complete? What is missing? What, if anything, could be added? The results provided by all groups formed the basis for the survey's questionnaire creation.

\section{Literature review}

Rural attractiveness is practically not defined, but instead limits itself to descriptions and explanations from various authors. Usually, rural attractiveness is more linked with competitiveness of territories, attractiveness investment, as well as development of tourism. Besides, it is largely related to landscapes, their quality and attractiveness. Factors and indicators that make up attractiveness are based on territorial capital (i.e. environmental, anthropic, economic, social-cultural, human and institutional capital) and assets [4].

The economic development and well-being of rural areas and people can be stimulated in many ways - for example, via new types of entrepreneurship (multifunctional agriculture, tourism, social entrepreneurship, public services, etc.); new forms of networking and cooperation (social innovations, sharing, crowdfunding, etc.); new sources of knowledge and innovation (i.e. vocational education and training, lifelong learning and distance learning, local knowledge) [4].

The well-being of regional and rural inhabitants is a crucial policy issue [14]. Factors shaping the quality of life range from income and jobs to education and civic participation. Many of the most influential factors for people's well-being are local issues, such as employment, access to health services, pollution and security. OECD [14] considers that improving lives entails making the places where people live better.

'Attractiveness' is a complex and multifaceted set of characteristics; the relative balance of factors varies depending on the groups that are at the centre of attraction strategies [15-16]. A key component of research into regional development is the identification of roles that environmental, physical and social attributes play in reinforcing (or diminishing) regional attractiveness for each stakeholder group. Barbovic et al. [17] conclude that attractiveness is concentrated always around two main factors: 1) human factor on one side, and 2) business factor on the other, where the human-business sphere can be perfectly mixed with time factors. Kuhmonen et al. [18] have added an immaterial welfare.

Although it is generally recognised that territorial capital is a crucial dimension of the attractiveness of places, there are many different views on what the territorial capital should encompass: environmental, anthropic, economic, social-cultural, human or institutional capital?

The choice and assessment of different types of capital and assets usually depend on the size of a given territory (state, region, municipality), and on target/stakeholder groups. The latter can be further differentiated by sector, (e.g. public, NGOs, governmental), field (e.g. agriculture, tourism, forestry, 
ITC), socio-demographic groups (inhabitants, new entrants/new comers, visitors, etc.; age, gender, prosperity and health state, etc.), education levels [4].

As a result, attractiveness becomes "a place-specific asset that guarantees some kind of socioeconomic stability". Nature's benefits to people include the provision of biodiversity and ecosystems [19]. By definition, all nature's benefits have human value, which can range from spiritual inspiration to market value. Most benefits, however, depend on the joint contribution of nature and anthropogenic assets [19], and provide to people good quality of life.

\section{Questionnaire survey}

The data used for the definition of rural attractiveness was compiled and summarized. The average value (mean) of each definition was then calculated. In order to evaluate the priority of each definition, it is necessary to look at a set of different averages, since the results of the survey are influenced by the interests, subjective opinions and the specific time of the respondents.

The descriptive statistics were calculated based on the ranking of survey responses (Table 1). As it can be seen from the average values, the scores are similar across all definitions, except for the fifth one. This means that the fifth definition should be ranked first. During the priorities evaluation, it transpired that the first definition has the greatest variance, and should therefore be ranked fifth. However, seven respondents (20\%) ranked it fourth. In the end, a conclusion was reached to keep the first definition in fifth place, third definition in fourth place, and fourth definition in sixth place.

Table 1

Descriptive statistics of vision's definition prioritisation by respondents $(n=30)$

\begin{tabular}{|c|c|c|c|c|c|c|}
\hline \multirow{2}{*}{ Value name } & \multicolumn{7}{|c|}{ Vision's definition } \\
\cline { 2 - 7 } & $\mathbf{1}$ & $\mathbf{2}$ & $\mathbf{3}$ & $\mathbf{4}$ & $\mathbf{5}$ & $\mathbf{6}$ \\
\hline Mean & 3.40 & 3.20 & 3.70 & 3.80 & 2.67 & 3.43 \\
\hline SD & 1.87 & 1.45 & 1.44 & 1.97 & 1.60 & 1.76 \\
\hline Mode & 5.00 & 2.00 & 4.00 & 6.00 & 1.00 & 3.00 \\
\hline Median & 3.50 & 3.00 & 4.00 & 4.50 & 2.00 & 3.00 \\
\hline Priority of vision's definition & $\mathbf{5}$ & $\mathbf{2}$ & $\mathbf{4}$ & $\mathbf{6}$ & $\mathbf{1}$ & $\mathbf{3}$ \\
\hline
\end{tabular}

Rural attractiveness vision's definitions ranked by priority are presented in Table 2.

Table 2

Vision's definition of rural attractiveness, results of prioritization

\begin{tabular}{|c|l|c|}
\hline No & \multicolumn{1}{|c|}{ Vision's definition } & Priority \\
\hline 5 & $\begin{array}{l}\text { Rural attractiveness encompasses sustainable rural communities with access to high } \\
\text { quality public services, a thriving and diverse local economy where agriculture } \\
\text { related activities are complemented by sustainable tourism and other forms of } \\
\text { employment. There is an attractive, ecologically rich and accessible countryside in } \\
\text { which the environment and biodiversity are conserved and enhanced* }\end{array}$ & 1 \\
\hline 2 & $\begin{array}{l}\text { Rural attractiveness envisions a place where everyone wants to live, enjoy high- } \\
\text { quality services, proper infrastructure and community spirit, where jobs and living } \\
\text { opportunities abound, and where one can find healthy and resilient environment** }\end{array}$ & 2 \\
\hline 6 & $\begin{array}{l}\text { Rural attractiveness is all about vibrant, inclusive and sustainable rural communities, } \\
\text { supported by diversified rural economies and effective stewardship of environmental } \\
\text { resources and cultural heritage*** }\end{array}$ & 3 \\
\hline 3 & $\begin{array}{l}\text { Rural attractiveness aims to provide good quality of life, freedom to express oneself, } \\
\text { employment opportunities, and easy access to a city, good quality services and food. } \\
\text { It is a place surrounded by landscapes** }\end{array}$ & 4 \\
\hline 1 & $\begin{array}{l}\text { Rural attractiveness is when rural areas make effective use of rural assets to improve } \\
\text { an overall well-being and build strong and sustainable communities** }\end{array}$ & 5 \\
\hline 4 & $\begin{array}{l}\text { Rural attractiveness is a nice place to live and work, to achieve social, economic and } \\
\text { environmental potential** }\end{array}$ & 6 \\
\hline
\end{tabular}

* [20]; ** Created during brainstorming session; *** [21] 
The evaluation of the survey results confirms that the fifth definition of the vision of rural attractiveness has received the highest evaluation of the respondents - PoliRural consortium partners (Fig. 3).

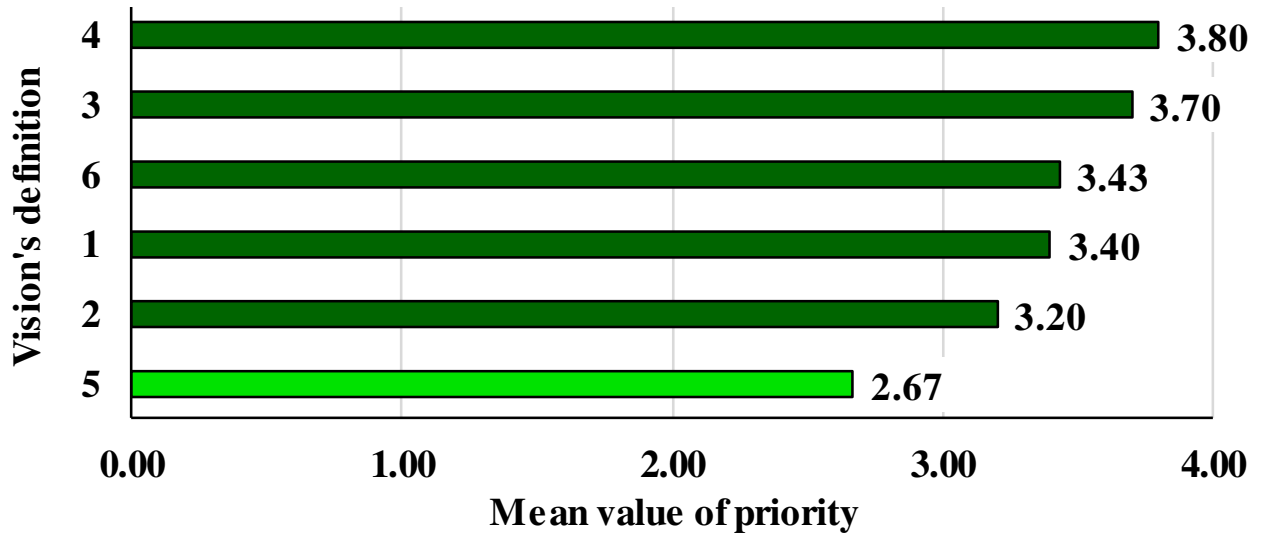

Fig. 3. Priority as mean values of rural attractiveness vision's definition $(n=30)$

The difficulties arising from multiple interpretation are also captured in the differing views of the PoliRural participants. As a result of the sequential steps of the PoliRural participants' brainstorming, literature review and survey (questionnaire with assigning points or scores), the initial vision of rural attractiveness was developed and offered for further improvement; in particular its definition, which received the highest assessment.

The initial definition is as follows: "Rural attractiveness encompasses sustainable rural communities with access to high quality public services, a thriving and diverse local economy where agriculture related activities are complemented by sustainable tourism and other forms of employment. There is an attractive, ecologically rich and accessible countryside in which the environment and biodiversity are conserved and enhanced". The vision is not final and will be updated several times during the project.

Recognising that sustainable development in rural areas, in which an economic growth and performance is indisputable basis or fundament for wellbeing of rural people, including provision of high quality of life, it may be possible to define rural attractiveness simply as "a viable, healthy and pleasant place to live, work and visit".

\section{Conclusions}

1. 'Attractiveness', including rural, is a complex and multifaceted set of characteristics; the relative balance of factors varies depending on the groups that are at the centre of attraction strategies. Besides, attractiveness is related with interaction of several important factors: human factor, business (socio-economic) factor, time factor, as well as immaterial - wellbeing or welfare factor. Where the latter also includes nature and environmental conditions.

2. Sustainable rural development is possible only if environmental, economic, social, human and cultural assets are fully harnessed.

3. The diverse opinions of respondents, as well as rural stakeholders make it difficult to come up with a single, one-size-fits-all definition of rural attractiveness.

4. As a result of the sequential steps of research, including internal activities - brainstorming of project's participants, and the survey (questionnaire with assigning points or scores), as well as the literature review, the initial vision of rural attractiveness was developed and offered for further improvement; in particular the definition, which received the highest assessment.

5. The created vision's definition is not final. As the project develops, the definition should be updated, and perhaps, another, more suitable and appropriate definition may be created, with more emphasis on the basic need of rural inhabitants-assurance of the wellbeing of rural people, including provision of high quality of life. 


\section{Acknowledgements}

The research leading to these results has received funding from the European Union's Horizon 2020 research and innovation programme under grant agreement No 818496. Project title is "Future Oriented Collaborative Policy Development for Rural Areas and People - PoliRural".

\section{References}

[1] 21c Starts a New Horizon Project on Rural Development. [online] [11.01.2020]. Available at: https://www.21cconsultancy.com/post/2019/06/24/21c-starts-a-new-horizon-project-on-ruraldevelopment

[2] POLIRURAL. D1.2 PoliRural Framework. 2019. 34 p. [online] [11.01.2020]. Available at: https://polirural.eu/resources/reports/

[3] Cork 2.0 Declaration. A Better Life in Rural Areas. 2016. 12 p. [online] [16.03.2020]. Available at: https://enrd.ec.europa.eu/cork-20-and-future-rural-development_en

[4] POLIRURAL. D1.1 Envisioning More Attractive Rural Places Professions. 2019. 80 p. [online] [09.01.2020]. Available at: https://polirural.eu/resources/reports/

[5] Venkatesh V., Brown S. A., Sullivan Y. W. Guidelines for conducting mixed-methods research: An extension and illustration. Journal of the Association for Information Systems, vol. 17(7), 2016, pp. 436-494.

[6] Creswell J. W. Research design: Qualitative, quantitative, and mixed methods approaches. Fourth edition. Thousand Oaks, CA: SAGE Publications. 2014. 342 p.

[7] Thomas J., Harden A. Methods for the thematic synthesis of qualitative research in systematic reviews. BMC medical research methodology, vol. 8(1), 2008, 45.

[8] Whittemore R, Knafl K. The integrative review: updated methodology. Journal of Advanced Nursing, vol. 52(5), 2005, pp. 546-553.

[9] Jackson S. L. Research methods and statistics: A critical thinking approach. Third edition. Belmont, CA: Wadsworth Cengage Learning. 2009. 430 p.

[10] Wiek A., Iwaniec D. Quality criteria for visions and visioning in sustainability science. Sustainability Science, vol. 9(4), 2014, pp. 497-512.

[11] Akinci C., Saunders M. N. Using questionnaire surveys for within organisation HRD research. In: M.N.K. Saunders P. Tosey (eds) Handbook of research methods on human resource development. Cheltenham: Edward Elgar, 2015, pp. 217-230.

[12] Creswell J. W., Poth C. N. Qualitative inquiry and research design: Choosing among five approaches. Thousand Oaks, CA Sage Publications. 2016. 488 p.

[13] Drisko J. W., Maschi T. Content analysis. New York, NY: Oxford University Press. 2016. 109 p.

[14] OECD. New Rural Policy: Linking Up For Growth. 2017, 36 p. [online] [31.03.2020]. Available at: https://www.oecd.org/rural/rural-development-conference/documents/New-Rural-Policy.pdf

[15] Servillo L., Atkinson R., Russo A. P. Territorial attractiveness in EU urban and spatial policy: a critical review and future research agenda. European Urban and Regional Studies, vol. 19(4), 2012, pp. 349-365.

[16] Russo A., Smith I., Atkinson R., Servillo L. A., Madsen B. et al. ATTREG. The Attractiveness of European regions and cities for residents and visitors. Final Report. University Rovira i Virgili. 2012. 97 p. [online] [17.01.2020]. Available at: https://www.espon.eu/programme/projects/espon2013/applied-research/attreg-attractiveness-european-regions-and-cities

[17] Barboric B., Baloh M., Zuti B., Podani K., Udvari B., Lukovics M. et al. Territorial attractiveness monitoring platform: a handbook for policy planners. Territorial Attractiveness Monitoring Platform: A Handbook for Policy Planners. 2018. 131 p. [online] [19.02.2020]. Available at: http://www.interreg-danube.eu/attractive-danube

[18] Kuhmonen T., Kuhmonen I., Luoto L. How do rural areas profile in the futures dreams by the Finnish youth?. Journal of Rural Studies, vol. 44, 2016, pp. 89-100.

[19] Diaz S., Demissew S., Joly C., Lonsdale W. M., Larigauderie A. A Rosetta Stone for nature's benefits to people. PLoS Biology, 13(1), 2015, e1002040.

[20] Scott A. J., Shorten J., Owen R., Owen I. What kind of countryside do the public want: community visions from Wales UK?. GeoJournal, vol. 76(4), 2011, pp. 417-436.

[21]European Rural Parliament. European Rural Manifesto. 2015. 6 p. [online] [19.03.2020]. Available at: http://www.europeanruralparliament.com 